\title{
A Step-by Step Process in Designing Personalized Reading Content for Slow Learner Children
}

\author{
Marzita Mansor ${ }^{1}$, Wan Adilah binti Wan Adnan² and Natrah binti Abdullah ${ }^{2}$ \\ ${ }^{1}$ Department of Computing, Universiti Pendidikan Sultan Idris, Malaysia. \\ ${ }^{2}$ Universiti Teknologi Mara, Malaysia.
}

Article History

Received:

22.09.2019

Revised:

28.10.2019

Accepted:

25.11.2019

*Corresponding Author:

Marzita Mansor

Email:

marzita@fskik.upsi.edu.my
Abstract: Teaching slow learner children in reading is a challenging process. It requires personalization touch which can deliver suitable reading materials to meet diverse slow learner existing knowledge, needs and preferences. However, despite the various implementation of the personalization in a wide range of areas, the implementation of existing teaching and learning in primary schools in Malaysia does not support personalization. With an intention to cater to slow learner reading difficulties, this research offers a step-by-step process of designing personalization of reading content for slow learner children. In conclusion, developing personalized reading content for the slow learner children is one way of attaining the need for the slow learner children in reading. By offering personalization of reading for the slow learner children, perhaps it would be something interesting tool to be explored by a slow learner to break a code of reading successfully.

Keyword: Personalized Reading, Slow Learner Children, Mapping, Content Personalization, Interface. 


\section{Introduction}

Over the past two decades and still, personalization have attracted increasing attention and has been considered for development of application in a wide range of study ranging from education, marketing, health, web usage and many more. Personalization which provides personal touch to individual as a user also provides positive impact to a diversity of users such as, students with diverse characteristics, elderly with variety of needs and individual user with unique preferences. In education, personalization can be considered as important concept that is used widely in education area due to its capability to provide solution for variety of students with different needs. Practically, the personalization provide user with the information that is only relevant and adapted information based on the user needs, suitable with the prior knowledge of the user. Successful personalization adapted to the technology use must be able to take into account the different characteristics of the user and all contextual situation occur during interaction with the personalized solution developed. This study shows how to implement content personalization for the slow learner children aged 9 years old in primary school. Content personalization is a key of providing suitable content for the slow learner children. Successfully determine suitable and personalized learning content would be a solution to help the slow learner dealing with their reading difficulties. Menyuk \& Brisk [1] point of view in his book entitled Language Development and Education, also have stated that in order to overcome learning difficulties of children in language, we need to clear understand on what kind of problems that each of these children encountered.

Menyuk \& Brisk [1] also stated that there are a number of language problems that begin to emerge for children between 6 to 9 years. Similarly with the triangle model of reading by Seidernberg [2] that emphasizes on the process of mastery reading through enhancing decoding (phonology), spelling (orthography) and meaning (semantic). Thus, before development of reading materials for the children, it is very crucial to examine their performance in each of Seidenberg reading component. Realizing the important of understanding user as main indicator for successful implementation of personalization this study have a look in depth analysis on the specific user which needs personalization as a tool to help them to excel in reading. Other than that, in order to be more focus, this study concentrate on the reading aspect of slow learner children context in primary school children.

This study also is initiated to overcome slow learner reading difficulties that always be a barrier for them to success. By personalizing reading material of the slow learner, it will enable these children to obtain reading materials matching with their reading ability and needs which includes customizing the corresponding reading activities based on their preferences.

Structures of this paper are as follows; firstly we presented this paper using step by step process of developing personalized reading content by starting with the data collection using qualitative approach. Then the flow of this paper continue to the next process of analyzing data collection which will leads to development of a use profile. Then, we do the mapping between user profiles created with the existing reading model. Finally we present an example of a case study for development of personalized reading content to show the process of personalization in order to demonstrate how content personalization is developed.

\section{Collecting Data for a Case Study}

In this study, qualitative design approaches was conducted to collect data from primary slow learner children. Data collection process involved several activities that leads to several outcomes. In brief, there are three main activities involved:

1. Interview Session with one Primary School children

2. Observation on slow learner children performing their reading activities in class session.

3. Document Analysis

In general, the first consideration before the data collection process begin, it is compulsory for us as the researcher to understand the teaching and learning reading conducted at school. Basically, once the children has entered for a school at the age of seven (7), firstly the school teacher will have to conduct simple examination in order to categorize the children based on their performance in reading. Performed children are given the opportunity to be in the first class compare to underperformed children. However, once the allocation of the children has been conducted, all children regardless of which class that they are belong to are treated the same, including reading materials used in their class 
Marzita Mansor, Wan Adilah Wan Adnan, Natrah Abdullah.

A Step-by Step Process in Designing Personalized Reading Content for Slow Learner Children.

International Journal of Humanities, Management and Social Sciences, vol. 2, no. 2, pp. 95-102, Dec. 2019. DOI: 10.36079/lamintang.ij-humass-0202.38

as well as their reading assessment. The act of using similar materials for all children is not efficient. We presented here the personalization of reading content to be used by the slow learner children as an alternative solution to support teaching and learning reading at school.

Listed here are reading construct that should be master by school children in primary school in learning process of reading. LINUS Screening program will be conducted from time to time. During the class, the teacher will be examining all children reading performance and assess them according to the LINUS Construct as shown in Table 1.

Table 1. LINUS Construct

\begin{tabular}{|c|l|}
\hline CONSTRUCT & \multicolumn{1}{c|}{ DESCRIPTION } \\
\hline K1: & Ability to sound and write vowel and consonant \\
\hline K2: & Ability to sound and write open syllable \\
\hline K3: & Ability to read and write open syllable \\
\hline K4: & Ability to sound and write close syllable \\
\hline K5: & Ability to read and write close syllable \\
\hline K6: & Ability to read and write word which contains 'ng' closed syllable \\
\hline K7: & $\begin{array}{l}\text { Ability to read and write word which contains } \\
\text { single vowel syllable }\end{array}$ \\
\hline K8: & $\begin{array}{l}\text { Ability to read and write word which contains } \\
\text { diphthong and cooperative vowel }\end{array}$ \\
\hline K9: & $\begin{array}{l}\text { Ability to read and write word which contains digraph and cooperative } \\
\text { consonant }\end{array}$ \\
\hline K10: & Ability to read and write word is with prefix and suffix \\
\hline K11: & Ability to read and write simple sentences \\
\hline K12: & Ability to read and understand stimulation material orally and in writing \\
\hline
\end{tabular}

\section{Analysis Data of Slow Learner}

Analysis of the slow learner children involved the process of categorization of slow learner children into each categories that the children belongs to. This process require us to take a look on slow learner existing reading knowledge, classify them according to their reading performance. Needs and preferences are useful information that is carried by each slow learner which the attributes belongs too.

Slow learner profile contains information on the followings; reading ability, reading needs and reading preferences as shown by Figure 1.

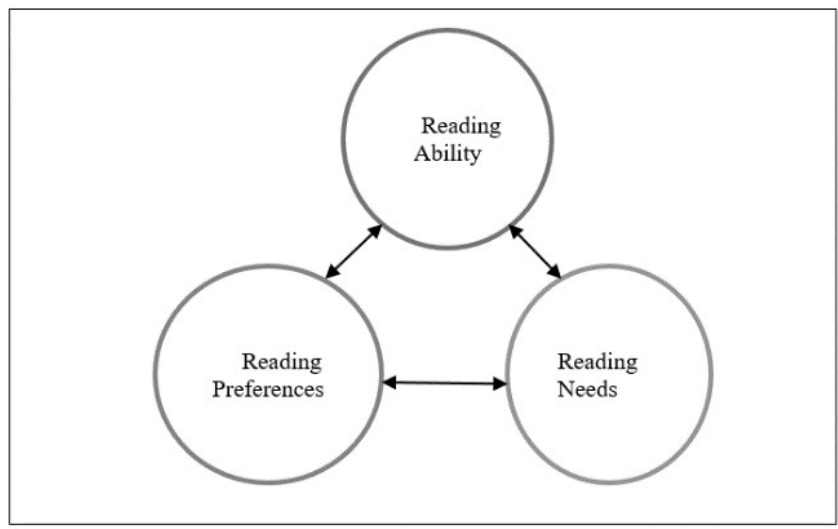

Figure 1. User Profile Development Includes Three Types of Information 
Marzita Mansor, Wan Adilah Wan Adnan, Natrah Abdullah.

A Step-by Step Process in Designing Personalized Reading Content for Slow Learner Children.

In the development of personalized user interface for slow learner children, the information of slow learner information are collected and user profiles are developed. User profiles are vital components that is widely used as a foundation for the implementation of personalized approach due to its capability to describe necessary information on particular users $[3,4,5]$. In this paper, user profile information is used for the development of specific learning content. In particular, total number of respondents involved in this study is 13 slow learner children and one remedial teacher who deal with the children in their remedial class. User profiles are developed in order to classify the user according to which groups they are belong. The process of development of user profile starts firstly, by gathering data from user and classifying according the reading ability from LINUS test result. The reading ability (RA) is used as a foundation for user profile classification. By grouping the children through similar RA, it would be easier to provide solution for the children reading difficulties.

For the development of the personalization content, individual reading ability is analysed based LINUS result. The LINUS result which is measured by reading constructs are used as a foundation in understanding the exact difficulties that each slow learner reading difficulties. From analysis performed, reading problem that is found to be varied as describe in the following Table 2 .

Table 2. Result of Reading Construct Of the Slow Learner

\begin{tabular}{|c|c|c|c|}
\hline Reading Construct & $\begin{array}{c}\text { Categories of } \\
\text { Reading Ability }\end{array}$ & $\begin{array}{c}\text { Description on } \\
\text { Reading Ability }\end{array}$ & $\begin{array}{c}\text { No of Slow } \\
\text { Learner }\end{array}$ \\
\hline K2 & Phonology & Decoding & 1 \\
\hline K3 & Orthology & Word Recognition & 5 \\
\hline K4 & Phonology & Decoding & 1 \\
\hline K6 & Orthology & Word Recognition & 1 \\
\hline K11 & Semantic & Meaning & 2 \\
\hline K12 & Semantic & Meaning & 3 \\
\hline
\end{tabular}

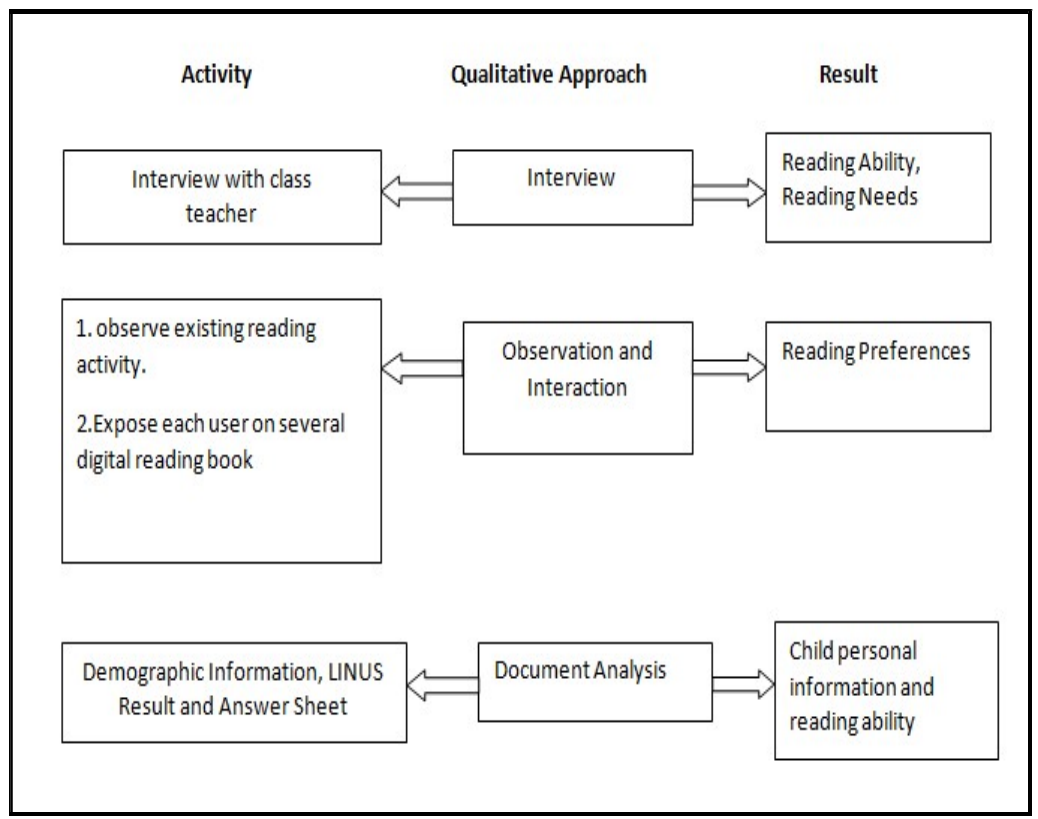

Figure 2. Data Collection Process 
Figure 2 indicates activities involves in data collection activities and outcomes of each activities performed.

\section{Breaking Codes of Reading through Mapping Technique}

Reading is like breaking a code. In order to break a code, then we must get a clue to present the code in the context of meaningful language. In particular, the code breaking require a reader to be able to understanding and master three important cycles of reading model; the orthological, phonological and semantic activity includes in performing reading activities.

By understanding on how to perform all activities in the reading model enable the novice reader to break the reading code and with enthusiasm to read, the reading ability would be an interesting journey to be explored. Below figure illustrates reading model that has been adapted in the development of personalized content design.

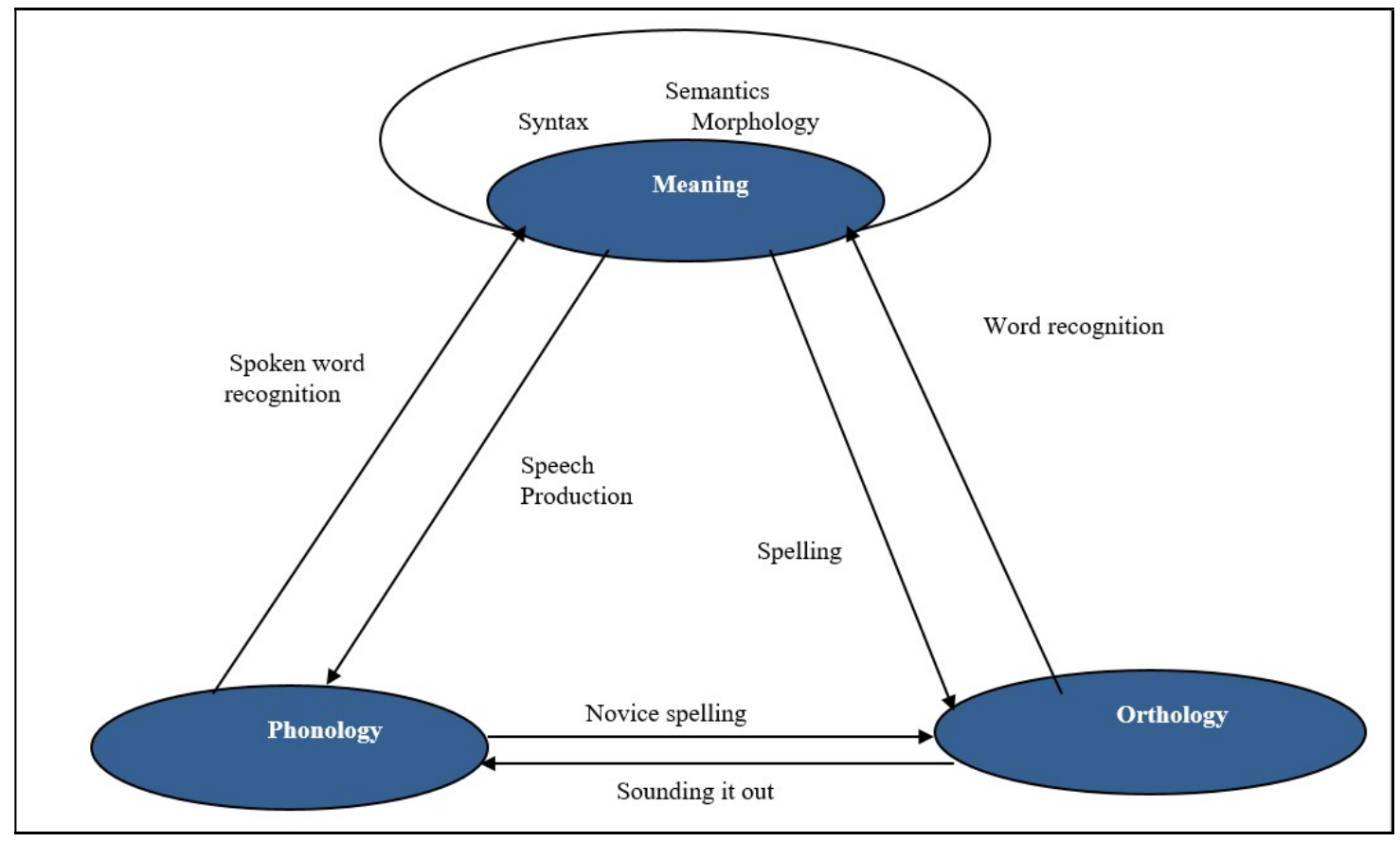

Figure 3. Theoretical Framework Also Known as Triangle Model of Reading [6]

In brief, this triangle model from the theoretical framework proposed by Seidenberg indirectly provides a simple tips of breaking a reading code. In general, the triangle model of reading emphasizes on the importance of word recognition, pronunciation of words and relation of words with the meaning. Parallel with the study conducted by Donna M. Scanlon [5] mentioned that in general reading activity involves several important skills. According to her, in order to be a successful reader a person should be able to read the words, retrieve the word's meanings and assemble words to form idea units. There are three important codes or activities involve in this reading model. Although there is no consensus on the sequences of activities in the reading model, it is suggested that a beginning reader to perform orthology activity as a first steps.

In regards to the concept of breaking a reading code, firstly, reader need to break the orthology code. Basically, orthology refer to the science of using a correct words in learning language. The orthology concerns on the selection of the right words in reading. The orthology process involves the process of recognizing the visual look of the letter or the words to form a letter into meaningful words. For example beginning reader will try to assemble a word such as 'ca'+ 'ke' to represent cake. 
By mastering orthology, beginning reader should be able to form a correct combination of these four letters into cake that is meaningful word [6]. The next code to break by a beginner reader is the phonology code. The phonology refers to the process involves the sounds of language recognizes by the visual look of the words learned by the orthology process. The sounds of language in phonology is called phoneme which stress on how to pronounce recognizable words in a correct way as preparation for the beginner reader to read correctly.

Donna M. Scanlon [7] mentioned that understanding phoneme require the ability to capture the meaning of unfamiliar words by translating groups of letters back into the sounds that they represent, link them to one's verbal vocabulary, and access their meaning. So, in order for the child learn reading in the phonology activity, the child need to map the recognizable letter learn in the orthology process and pronounce it correctly. After breaking two codes in the orthology and phonology codes describe before, the last code need to be break is by understanding the meaning of the words that has been view visually and pronounced. The study of the meaning also require several understanding on the important terms related to meaning including syntax, semantics and morphology $[8,9,10]$.

Understanding on these three important terms, which cover the arrangement of the alphabets in a words, the words formulation and meaning enable the beginning reader to apply their intellectual ability to start reading by thinking.

However, according to Kaufmann [8] language learning is not primarily an intellectual activity. It requires enthusiasm and repeated and concentrated exposure to language contexts that become familiar over time. Enthusiasm leads to interest and expanding language ability. Thus, it help beginning reader such as the slow learner children to learn their own ways by concerning on embedding reading materials that interest them to read but not forgetting to put the priority on the reading contents suit with their reading needs. Although the rule of breaking a code suggest a new reader to start with the orthology activities, for the purpose of this study, the slow learner children can starts from which reading ability that they able to perform.

In order to help slow learner children breaking a code of reading, analysis of reading ability that the slow learner children have is a compulsory. Firstly, LINUS reading result is identified based on LINUS test conducted at their own school. Then with the assistance from their respective teacher, their reading difficulties are confirmed. LINUS result categorizes students with the capability of reading based on several reading construct.

\section{Mapping Content Personalization}

Personalization provides user with the only information that is relevant and adapted information based on the user needs, suitable with the prior knowledge of the user and adapted information to his need [10]. Successful personalization adapted to the technology use must be able to take into account the different characteristics of the user and all contextual situation occur during interaction with the personalized solution developed.

Differences in reading performance of the slow learner children require personalization aspect to be implemented. The next steps after identification of reading ability of the slow learner children is to map reading ability with the reading model and identify suitable reading content for each category. Below figures illustrate the mapping process to determine the right reading content for slow learner children. The process starts with the mapping of the triangle model of reading, the orthology (word recognition), phonology (decoding) and semantic (meaning) activities with the reading ability of all respondents that was determine by LINUS result. All respondents participated in this research has been classified into several groups according to their reading ability.

All information for content personalization is related on reading ability, reading needs, reading difficulties and reading preferences. Only related information to reading of slow learner children is consider as elements in the content design due to understanding of slow learner ability in reading leads to better design. While reading ability is used as a foundation in determining personalized reading content of the slow learner children, the needs and preferences of the slow learner serves to keep the slow learner engagement in reading material provides. Identified needs and preferences is depending on each slow learner unique profile. 
Marzita Mansor, Wan Adilah Wan Adnan, Natrah Abdullah.

A Step-by Step Process in Designing Personalized Reading Content for Slow Learner Children.

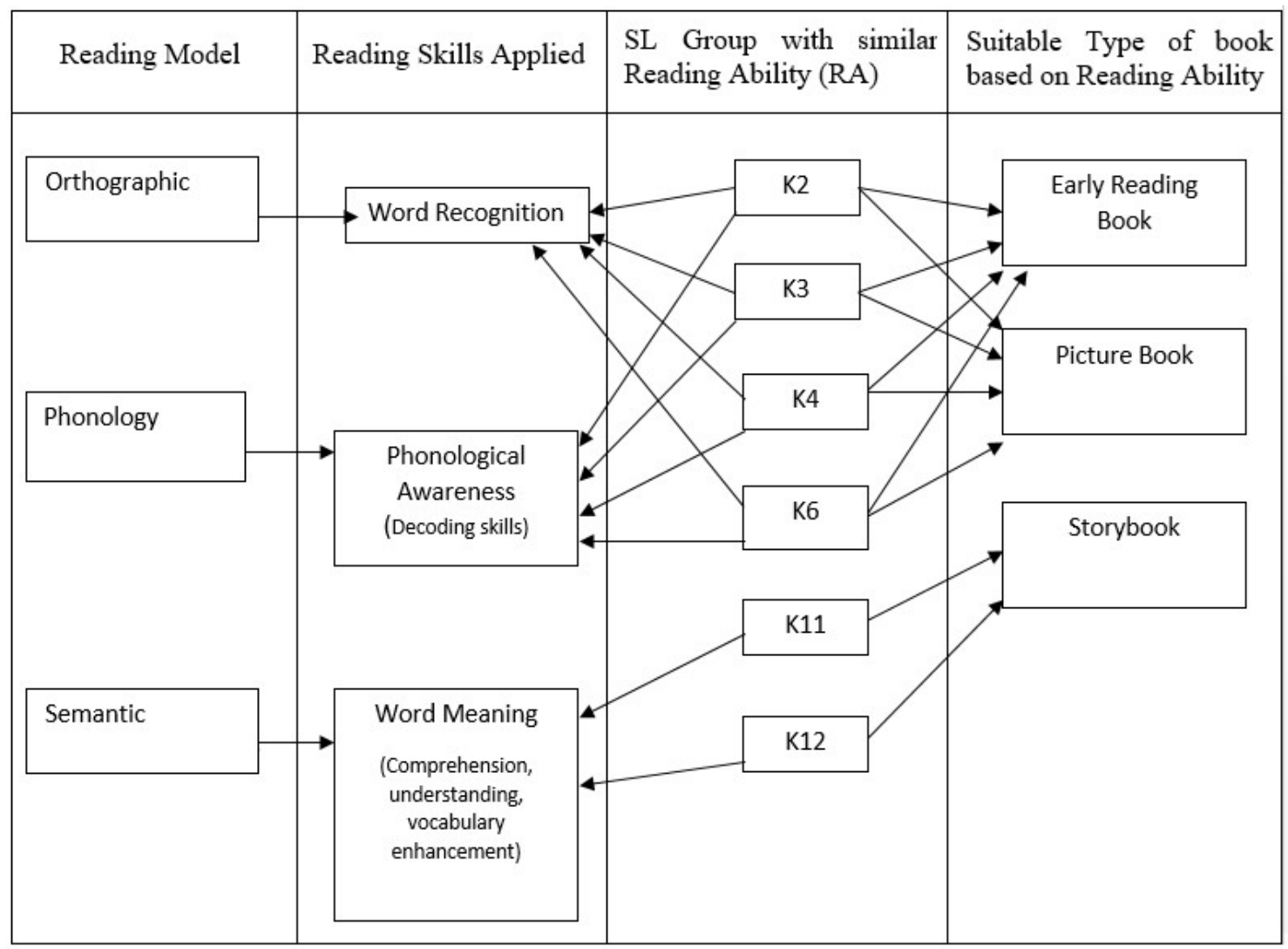

Figure 4. Mapping of Reading Model with Reading Ability of Slow Learner Children

\section{Conclusion}

Personalization is interesting approach to teaching and learning. Personalization approach which consider user as a basic foundation in the design provides opportunity for the designer to explore variety of design based on each individual user knowledge, needs and preferences. Thus, the personalization can be expanded for the development of various topic in education and a variety of users. The basic key to successful personalization is understanding user profile. When the user profile and personalization tools combined together, the aim to provide affective teaching and learning which is something more interesting to be explored, enjoyed and engaged is possible to be implemented in the perspective of individual user.

\section{References}

[1] P. Menyuk and M. E. Brisk, "Language Development in Early Childhood - The Pre-school Years: Ages 3-5," in Language Development and Education. Palgrave Macmillan, London, 2005.

[2] S. Cakula and M. Sedleniece, "Development of a personalized e-learning model using methods of ontology," Procedia Computer Science, vol. 26, pp. 113-120, oktober 2013. [Online]. Available: https://doi.org/10.1016/j.procs.2013.12.011. [Accessed: March 2019].

[3] B. Saleena and S. K. Srivatsa, "Using concept similarity in cross ontology for adaptive eLearning systems," Journal of King Saud University - Computer and Information Sciences, vol. 27, no. 1, pp. 1-12, 2015. [Online]. Available: https://doi.org/10.1016/j.jksuci.2014.03.007. [Accessed: March 2019].

[4] A. Druin, Mobile Technology for Children: Designing for Interaction and Learning. (Elsevier, Ed.). Amsterdam: Morgan Kaufman Publishers, 2009. 
[5] W. O. Galitz, The Essential Guide to User Interface Design. Wiley (Second Edi). New York: Wiley Computer Publishing, 2002.

[6] M. S. Seidenberg and S. Seidenberg, "Connectionist Models of Word Reading," Curent Directions in Psychological Science, vol. 14, no. 5, pp. 238-242, 2014. [Online]. Available: https://doi.org/10.1007/978-1-4939-2993-1. [Accessed: March 2019].

[7] M. Scanlon and J. M. S. Donna, Early Intervention for Reading Difficulties: The Interactive Strategies Approach. New York: The Guilford Press, 2010.

[8] B. S. Kaufmann, A Personal Guide to Language Learning (2nd Edition). Canada: Authors House, 2005.

[9] S. Kanoje, S. Girase, and D. Mukhopadhyay, "User Profiling Trends, Techniques and Applications," International Journal of Advance Foundation and Research in Computer, vol. 1, no. 11 , pp. $2348-4853,2014$.

[10] C. Chen, "Personalized Intelligent Mobile Learning System for Supporting Effective English Learning Published by: International Forum of Educational Technology \& Society Personalized Intelligent Mobile Learni," International Forum of Educational Technology \& Society, vol. 11, no. 3, 2017. 